\title{
Regeneration of Spent Catalysts for Furfural Decarbonylation
}

\author{
Aliya Erkegulovna Bitemirova ${ }^{1}$, Haliya Bahadyrovna Alihanova ${ }^{2}$, Roza Spabekovna Spabekova ${ }^{3}$, Bibigul' $^{\text {' }}$ \\ Bekenova Shagrayeva ${ }^{1} \&$ Myrzabek Nysanbekovich Ermahanov $^{3}$ \\ ${ }^{1}$ South Kazakhstan State Pedagogical University, Shymkent, Kazakhstan \\ ${ }^{2}$ South Kazakhstan State Medical Academy, Shymkent, Kazakhstan \\ ${ }^{3}$ South Kazakhstan State University Named after of M. Auyezov, Shymkent, Kazakhstan \\ Correspondence: Aliya Erkegulovna Bitemirova, South Kazakhstan State Pedagogical University, Shymkent, \\ Kazakhstan. Tel: 73-770-1549-0762. E-mail: Bitemirova1960@mail.ru
}

Received: February 22, 2015

doi:10.5539/mas.v9n5p358
Accepted: March 15, 2015

Online Published: April 24, 2015

URL: http://dx.doi.org/10.5539/mas.v9n5p358

\begin{abstract}
The article discusses the reasons for the decontamination of industrial catalysts for furfural decarbonylation. Various methods for regenerating of the supported catalyst are studied. For example, organic and inorganic solvents were used for the regeneration of spent catalyst for obtaining industrial furan. To improve the activity of spent-regenerated samples of CDF-1 catalyst, the method of modifying with d-metals additives from aqueous solutions was applied. Iron, cobalt, and nickel were used as modifying additives.

Results for furfural decarbonylation on additives regenerated-modified with transitive d-metals batches of spent CDF-1 catalyst shows that implementing spent modifying additives to the regenerated catalyst increases the stability and activity. The article provides methods for regenerating spent CDF-1 catalyst, and modifying the regenerated catalyst and its reusing in the process of decarbonylation.
\end{abstract}

Keywords: regeneration, decarbonylation, supported catalysts, coking, modification, organic chemistry

\section{Introduction}

The reaction product of vapour-phase contact decarbonylation of furfural - furan - is the major intermediate product in the production of polyamide resins, synthetic rubber, polymer materials with particularly valuable properties, defoilants, herbicides, pharmaceuticals, and many other important industrial products. However, the current level of production of these products does not meet the increased needs of the national economy. This is because the commercial catalyst: palladium on carbon (CDF-1) possesses low throughput is complex in the preparation, and the processes on it are carried out at relatively stringent conditions, get resined quickly, and does not undergo regeneration. Thus, the development of new high-performance catalysts and furfural decarbonylation process intensification is a highly topical issue.

One of the promising areas for furfural to furan decarbonylation process intensification is the use of supported catalysts, due to their high activity, selectivity, stability, low cost and ease of preparation.

The level of the modern chemical industry is determined by the perfection of catalysts and catalytic processes. Consistency of activity and selectivity of the catalysts for a long time requires stability and durability of their continuous operation. However, there are many reasons for the catalysts activity reduction during operation (Samahov, A. A., Seidman et al., 1976), and coking during processing of hydrocarbons is the most common among them (Byanov, R. A., 1967).

This harmful process accompanies the majority of modern industrial catalytic reactions. The term "coking" means packing products, carbonaceous deposits, carbon, resins, etc. All of these products are formed either as packing products on catalysts or under the influence of rised temperatures during hydrocarbons processing. Catalysts coking causes a change in their basic characteristics (Bitemirova et al., 2013). The activity and often selectivity of catalysts are reduced. In practice, this leads to very serious consequences. The process becomes periodic, cyclic with shutdown of the reactor for catalyst regeneration. This increases expenses for catalysts, and capital and operating costs. The history of the modern technological schemes and industrial equipment design processes such as catalytic hydrogenation, decarbonylation, cracking, reforming and platforming, dehydrogenation, hydrocracking, hydrotreating, etc. is closely connected with the problem of overcoming the 
negative, sometimes decisive influence of coke formation on the catalyst, which occurs simultaneously with the main target product.

Typically, at catalysts coking, their activity decreases rapidly under the action of the first portions of coke as the result of their physical chemical deactivation.

Palladium catalysts used in the furan production rapidly get deactivated due to strong adsorption of furfural. In this regard, the author (Kramerova, G. E., 1988) discusses the causes of deactivation of furfural decarbonylation industrial catalysts. It is found that the catalysts coking is based on low heat resistance of furfural. The presence of impurities in the sulfur-containing substances causes poisoning of palladium. The furfural to furan decarbonylation area received significant contribution from Karmilchik A. Ya., Giller S. A. (Karmilchik, A. Ya, Giller, S. A. 1970, 1976), Sokolov, V. N., et al. (Sokolov et al., 1981). They offered optimal catalysts and furfural into furan decarbonylation method. However, the issues of increasing the catalysts life, the development of new methods to regenerate spent catalyst got practically no decisions.

\section{Materials and Methods}

Coking rate can be reduced by stabilising catalysts in oxidized state. Such stabilization is often carried out in practice by dilution of hydrocarbons with steam. Dilution of hydrocarbons by water steam has a significant effect when the catalysts comprise oxides or other compounds of Fe, Co, Ni, Cr (Buyanov, R. A., 1983). This not only reduces coking greatly, but also the catalyst durability is ensured.

The paper by (Babenko, V. S., Buyanov et al., 1979) studies the iron coked catalyst regeneration by argon-oxygen mixture with oxygen content of $0.5-20.0 \%$. It is shown that carbonaceous deposits burn off occurs stepwise.

The mechanism of coke burn off with carbonised oxides of cobalt, nickel, and chromium is studied (Caca, J., Morrondo, E. S., Parra, J. B. Sostre, H., 1982). It has been established that the catalytic carbon burn off occurs due to the formation of metal oxides. In this case, the metal oxides catalyse the oxidation of carbonaceous deposits. The effect of potassium additives promoting in an amount of from 0.1 to $23 \mathrm{wt} \%$ is studied in the context of effect on the process for iron oxide carbonaceous deposits burn off in the temperature range $450-700^{\circ} \mathrm{C}$ (Babenko, V. S., 1983). At temperatures below $550^{\circ} \mathrm{C}$, potassium forms an independent active phase of carbonate, accelerating the process of carbon burn off at temperatures above $550^{\circ} \mathrm{C}$, the promotional effect is observed when the concentration of potassium $<\sim 8.9 \mathrm{wt} . \%$ due to the increase of the bond energy of oxygen in the iron oxide lattice. The increase in the potassium content above $8-9 \mathrm{wt} . \%$ leads to coating of iron oxide surface with potassium ferrite and slowing down the regeneration process. The paper by (Babenko et al., 1982) examines the connection between the content of $\mathrm{Cr}^{6+}$ ions in the initial non-carbonised catalyst and their activity in its carbonisation and regeneration. It is shown that $\mathrm{Cr}^{6+}$ ions contribute to catalytic carbon burn off. Babenko, V. S. (Babenko et al., 1986) carried out the research of carbonaceous deposits burn off on iron oxide promoted with metals (see Table 1).

Alkaline additives can be arranged in the following series according to the influence on the regeneration rate at 923K: $\mathrm{Li}<\mathrm{K}<\mathrm{Rb}<\mathrm{Na}<\mathrm{Cs}$. The nature of effect of alkali metal additives to iron oxide on the coke burn off process depends on the regeneration temperature.

Table 1. Carbonaceous deposits burn off on iron oxide promoted by alkali metals $\left(923 \mathrm{~K}, \mathrm{P}_{\mathrm{O}_{2}}=1,0 \quad\right.$ vol. $\%$; carbon content $32 \%$ by weight)

\begin{tabular}{ccccccccccc}
\hline Promoting additive & $\begin{array}{c}\text { Alkali metal } \\
\text { content, } \%\end{array}$ & 5 & 10 & 20 & 30 & 40 & 50 & 60 & 90 \\
\cline { 3 - 9 } & & \multicolumn{8}{c}{ Concentration of the disengaged $\mathrm{CO}_{2} \cdot 10}$, & vol.\% \\
No additive & - & 0.3 & 0.35 & 0.40 & 0.42 & 0.42 & 0.38 & 0.28 & 0.03 \\
$\mathrm{Li}$ & 0.4 & 0.31 & 0.35 & 0.40 & 0.42 & 0.39 & 0.34 & 0.30 & 0.06 \\
$\mathrm{Na}$ & 1.2 & 0.46 & 0.56 & 0.56 & 0.54 & 0.56 & 0.42 & 0.23 & 0.01 \\
$\mathrm{~K}$ & 2.0 & 0.32 & 0.37 & 0.42 & 0.44 & 0.46 & 0.43 & 0.31 & 0.03 \\
$\mathrm{Rb}$ & 4.4 & 0.34 & 0.39 & 0.47 & 0.52 & 0.50 & 0.43 & 0.30 & 0.02 \\
$\mathrm{Cs}$ & 6.8 & 0.46 & 0.56 & 0.57 & 0.54 & 0.51 & 0.43 & 0.28 & 0.01 \\
\hline
\end{tabular}

At high temperatures $(>773-873 \mathrm{~K})$ for lithium $\left.>\sim 743^{\circ} \mathrm{K}\right]$, alkali metals are binded by iron oxide to the corresponding ferrites, catalyst activity in the regeneration process will be, according to the authors, determined 
by the bond energy of oxygen in an alkali metal ferrite. At low temperatures of regeneration, alkali metals will be mainly in the form of separate phases of metal carbonates possessing catalytic activity in the carbon oxidation process, and the activity of the catalyst increases with increasing ion radius of the alkali metal.

Babenko, V. S. (Babenko, V. S., \& Buyanov, R. A. 1986) examined patterns of self-regeneration of iron potassium oxide catalysts in the presence of water vapour. Samples were carbonised by butadiene-1.3 at $923 \mathrm{~K}$. Regeneration was performed directly in the medium after carbonisation in steam and steam-oxygen environment $\left(0.5 \mathrm{vol} . \% \mathrm{O}_{2}\right.$ at $\left.723-923 \mathrm{~K}\right)$. It is shown that the essence of self-regeneration of catalysts is in the oxidation of intermediates in the physically adsorbed or chemically bound to the catalyst state due to the water oxygen and oxygen in the reaction medium during the formation of carbonaceous deposits. The main contribution to the self-regeneration comes from the process of the intermediate carbide compounds hydrolysis.

Kramerova G. (Kramerova G., 1988) offers successive heat treatment in hydrogen and oxygen containing gas for the regeneration of spent palladium catalyst furfural decarbonylation. The catalyst activity is fully restored. Resin products, deposited on the furfural columns plates in distilleries, are extracted by diethyl ether, acetone, and methyl ethyl ketone (Fedotova, S. A., \& Tsirmin, Yu. A., 1975). Wherein extracted fatty acids are unsaturated acid of the $\mathrm{C}_{\mathrm{n}} \mathrm{H}_{2 \mathrm{n}-2} \mathrm{O}_{2}$ type. The column plates from the resinous substances shall be cleaned by $3-5 \%$ hot alkali solution.

Many well-known methods of furfural and FS stabilization are focused on the way to slow down the process of autoxidation and gumming. Furfural and FS molecules stability against acids is increased by reagents promoting reduction of the electron density in the core. Reagents such as nucleophiles can have an inhibitory effect, thereby stabilizing the product. It is generally known that nucleophilic reagents include amines that give their lone pair of electrons when participating in the reaction.

The methods for purificating equipment from resin contamination include: chemical, mechanical, chemical and mechanical, and thermal methods. A special role among the cleaning solutions components belongs to SAW surfactants. They have dispersing and emulsifying action onto solid contaminants, and act as blowing agent on liquid contaminants. Organic solvents have high cleaning power and virtually no corrosive effect on the cleaned metal surfaces, but are expensive and often not easy to handle (toxic, flammable, short-lived). Cleaning solutions for resinous substances also include caustic, soda ash, surfactants, water glass, etc.

Gardos G. et al. (Gardos, G., Pechy, Z., Csaszar, E., Redey, A., 1976) exmanined the composition of the precipitate distillation columns for FS production and the efficiency of dissoluting in various solvents of furfural and FS precipitation production. It is shown that the FS production precipitation consists of organic substances nature by at $71-88 \%$. Mineral portion of precipitation (12-29\%) is a catalyst component $(\mathrm{Cu}, \mathrm{Cr}, \mathrm{Ca}, \mathrm{Ba}$, and $\mathrm{Fe}$ of the graph). The best solvent is $\mathrm{HNO}_{3}$. At $80^{\circ} \mathrm{C}$, the level of precipitation dissolution in 10,20 and $30 \% \mathrm{HNO}_{3}$ during $30 \mathrm{hrs}$, is $\sim 98 \%$. Good solvent can be FS as well, the dissolution rate of precipitation in FS constituted $29 \%$. In order to reduce the rate of resin formation in the FS production, stabilized and freshly distilled furfural shall be used, as well as implemented effective regime for vacuum-rectification of hydrogenation product. Purification of distillation column is provided by furfuryl alcohol or $10 \% \mathrm{HNO}_{3}$ solution at $70-80^{\circ} \mathrm{C}$ applied overnight.

Thus, from the foregoing one can conclude that the research of the gumming process and regeneration of spent catalysts is of great theoretical and practical importance. The elaboration of the best ways for catalyst regeneration is the most urgent problem facing the chemical engineer.

Beysekov et al. (Beysekov, T. B., Bitemirova et al., 1990) theoretically and experimentally substantiated the new method of regeneration for coked $\mathrm{Pd} / \mathrm{C}$ catalyst in a gas mixture of carbon dioxide-air, eliminating local overheating of the catalyst.

In the absence of palladium, coal starts to lose mechanical strength and disintegrate at temperatures above $400^{\circ} \mathrm{C}$ (Table 2), and under the influence of palladium, accelerating the oxidation; the reaction of carbon with oxygen carrier begins at $360-380^{\circ} \mathrm{C}$. When treated with gas mixture of carbon dioxide-air of the coked catalyst, it is possible to remove substantially all of the coke at $330-340^{\circ} \mathrm{C}$, while maintaining the mechanical strength of the catalyst. It is noted also that the catalysts on carbon mediums shall pass through pretreatment with hydrogen to reduce coke burn off, which allows completely restoration of the catalyst activity.

In this paper, various inorganic and organic solvents make the regeneration of spent industrial CDF-1 catalyst. Among them, the most optimal were oxalic acid aqueous solution and its mixture with $95 \%$ (Bitemirova AE 2013) ethanol. 
Table 2. Data on refeneration of $\mathrm{Pd} / \mathrm{C}$ catalyst

\begin{tabular}{cccccc}
\hline $\begin{array}{c}\text { Concentration, } \mathrm{O}_{2}, \\
\text { vol.\% }\end{array}$ & $\begin{array}{c}\text { Volumetric } \\
\text { ratio of } \\
\mathrm{O}_{2}: \mathrm{CO}_{2}\end{array}$ & Temperature, ${ }^{0} \mathrm{C}$ & Duration $\mathrm{r}$ & $\begin{array}{c}\text { Amount of the } \\
\text { burn off coke, } \\
\text { mass \% }\end{array}$ & $\begin{array}{c}\text { Burning speed, } \\
\Gamma_{\mathrm{c}} / \Gamma_{\text {кат. }} \mathrm{c} \cdot 10^{5}\end{array}$ \\
\hline 5 & $1: 15$ & $300-310$ & 12.5 & 98.9 & 0.14 \\
7 & $1: 7$ & $310-340$ & 11.0 & 99.2 & 0.14 \\
4 & $01: 18$ & $280-290$ & 35.4 & 96.5 & 0.09 \\
10 & $1: 4$ & $410-420$ & \multicolumn{2}{c}{ Destruction of the coal carrier } \\
\hline
\end{tabular}

Table 3 shows the results for furfural decarbonylation on regenerated CDF-1.

Table 3. Furfural decarbonylation on regenerated spent CDF-1 catalyst samples

\begin{tabular}{|c|c|c|c|c|c|c|c|c|c|c|c|}
\hline \multirow{2}{*}{$\mathrm{t},{ }^{0} \mathrm{C}$} & \multirow{2}{*}{$\begin{array}{l}\text { Experiment } \\
\text { time, hrs }\end{array}$} & \multirow{2}{*}{$\begin{array}{c}\text { Qty of the } \\
\text { supplied } \\
\text { furfural, } \\
\text { L }\end{array}$} & \multirow{2}{*}{$\begin{array}{l}\mathrm{W}_{\phi \phi}, \\
\mathrm{p}^{-1}\end{array}$} & \multicolumn{6}{|c|}{ Average decarbonylation products yields, $\%$} & \multirow[b]{2}{*}{ Activity, \% } & \multirow[b]{2}{*}{ Selectivity, $\%$} \\
\hline & & & & P. O. & S. N. & THF & B-1 & $\mathrm{FF}$ & $\mathrm{X}$ & & \\
\hline 1 & 2 & 3 & 4 & 5 & 6 & 7 & 8 & 9 & 10 & 11 & 12 \\
\hline \multicolumn{12}{|c|}{ Initial spent CDF-1 catalyst without regeneration } \\
\hline $260-300$ & 15 & 0.18 & 0.012 & 15.2 & 1.3 & 1.5 & 0.9 & 80.9 & - & 19.1 & 79.5 \\
\hline \multicolumn{12}{|c|}{ Spent CDF-1 catalyst, regenerated in the mixture } \\
\hline \multicolumn{12}{|c|}{$5 \% \mathrm{H}_{2} \mathrm{C}_{2} \mathrm{O}_{4}: 95 \% \mathrm{C}_{2} \mathrm{H}_{5} \mathrm{OH}=1: 1$ ( $\mathrm{t}_{\text {boiling }}=84,5$ ) during $3 \mathrm{hrs}$} \\
\hline $260-300$ & 20 & 0.24 & 0.012 & 19.3 & 1.5 & 1.3 & 0.7 & 77.0 & 0.05 & 23.0 & 83.9 \\
\hline \multicolumn{12}{|c|}{ Spent CDF-1 catalyst, regenerated in the mixture } \\
\hline \multicolumn{12}{|c|}{$10 \% \mathrm{H}_{2} \mathrm{C}_{2} \mathrm{O}_{4}: 95 \% \mathrm{C}_{2} \mathrm{H}_{5} \mathrm{OH}(1: 1)$ ( $\left.\mathrm{t}_{\text {boiling }}=82,5\right)$ during $3 \mathrm{hrs}$} \\
\hline $260-300$ & 30 & 0.36 & 0.012 & 31.0 & 0.86 & 0.8 & - & 67.0 & - & 33.0 & 94.0 \\
\hline \multicolumn{12}{|c|}{ Spent CDF-1 catalyst, regenerated in the mixture } \\
\hline \multicolumn{12}{|c|}{$20 \% \mathrm{H}_{2} \mathrm{C}_{2} \mathrm{O}_{4}: 95 \% \mathrm{C}_{2} \mathrm{H}_{5} \mathrm{OH}(1: 1)$ ( $\left.\mathrm{t}_{\text {boiling }}=81,5\right)$ during $3 \mathrm{hrs}$} \\
\hline $260-300$ & 33 & 0.396 & 0.012 & 34.3 & 1.0 & 1.3 & 0.05 & 63.3 & - & 36.7 & 93.5 \\
\hline \multicolumn{12}{|c|}{ Spent CDF-1 catalyst, regenerated in the mixture } \\
\hline \multicolumn{12}{|c|}{$10 \% \mathrm{H}_{2} \mathrm{C}_{2} \mathrm{O}_{4}: 95 \% \mathrm{C}_{2} \mathrm{H}_{5} \mathrm{OH}(1: 2)$ ( $\left.\mathrm{t}_{\text {boiling }}=83,0\right)$ during $3 \mathrm{hrs}$} \\
\hline $260-300$ & 25 & 0.3 & 0.012 & 26.5 & 1.5 & 0.9 & - & 71.0 & 0.05 & 29.0 & 91.4 \\
\hline \multicolumn{12}{|c|}{ Spent CDF-1 catalyst, regenerated in the mixture } \\
\hline \multicolumn{12}{|c|}{$10 \% \mathrm{H}_{2} \mathrm{C}_{2} \mathrm{O}_{4}: 95 \% \mathrm{C}_{2} \mathrm{H}_{5} \mathrm{OH}(1: 3)$ ( $\left.\mathrm{t}_{\text {boiling }}=83,5\right)$ during $3 \mathrm{hrs}$} \\
\hline $260-300$ & 21 & 0.0252 & 0.012 & 22.3 & 1.3 & 1.0 & 0.5 & 75.0 & - & 25.0 & 89.2 \\
\hline \multicolumn{12}{|c|}{ Spent CDF-1 catalyst, regenerated in the mixture } \\
\hline \multicolumn{12}{|c|}{$10 \% \mathrm{H}_{2} \mathrm{C}_{2} \mathrm{O}_{4}: 95 \% \mathrm{C}_{2} \mathrm{H}_{5} \mathrm{OH}(2: 1)$ ( $\left.\mathrm{t}_{\text {boiling }}=87,5\right)$ during $3 \mathrm{hrs}$} \\
\hline $260-300$ & 32 & 0.384 & 0.012 & 1.4 & 1.2 & - & & 64.0 & 0.05 & 36.0 & 91.7 \\
\hline \multicolumn{12}{|c|}{ Spent CDF-1 catalyst, regenerated in the mixture } \\
\hline \multicolumn{12}{|c|}{$10 \% \mathrm{H}_{2} \mathrm{C}_{2} \mathrm{O}_{4}: 95 \% \mathrm{C}_{2} \mathrm{H}_{5} \mathrm{OH}(3: 1)$ ( $\left.\mathrm{t}_{\text {boiling }}=89,8\right)$ during $3 \mathrm{hrs}$} \\
\hline $260-300$ & 35 & 0.42 & 0.012 & 34.6 & 1.4 & 1.0 & 0.5 & 62.4 & - & 37.6 & 92.0 \\
\hline \multicolumn{12}{|c|}{ Spent CDF- 1 catalyst, regenerated in the mixture } \\
\hline \multicolumn{12}{|c|}{$10 \% \mathrm{H}_{2} \mathrm{C}_{2} \mathrm{O}_{4}: 95 \% \mathrm{C}_{2} \mathrm{H}_{5} \mathrm{OH}(1: 1)$ during $1 \mathrm{hr}$} \\
\hline $260-300$ & 24 & 0.288 & 0.012 & 23.8 & 1.3 & 1.8 & - & 73.0 & 0.03 & 27.0 & 88.1 \\
\hline \multicolumn{12}{|c|}{ Spent CDF-1 catalyst, regenerated in the mixture } \\
\hline $260-300$ & 32 & 0.384 & 0.012 & 32.4 & 1.6 & 0.9 & - & 64.9 & 0.04 & 35.1 & 92.3 \\
\hline & & & Spent & DF-1 & alyst, 1 & enera & in the & ixture & & & \\
\hline & & & $10 \%$ & $\mathrm{H}_{2} \mathrm{C}_{2} \mathrm{O}_{4}$ & $5 \% \mathrm{C}_{2}$ & $\mathrm{OH}(1$ & durin & $\mathrm{hrs}$ & & & \\
\hline $260-300$ & 36 & 0.432 & 0.012 & 35.1 & 1.2 & 0.8 & - & 63.0 & 0.05 & 37.0 & 95.0 \\
\hline
\end{tabular}

Data from Table 3 shows that the initial spent industrial catalyst in the range of $260-300^{\circ} \mathrm{C}$ operates for 15 hours in total with an average yield of furan of $15.2 \%$, total activity of $19.1 \%$ and furan selectivity of $79.5 \%$, while its 
samples regenerated in mixtures "oxalic acid - 95\% ethanol" show higher activity, selectivity, and stability. Thus, increasing the concentration of oxalic acid in a mixture of 5 to $20 \%$, or in correlation of $10 \%$ oxalic acid: $95 \%$ $\mathrm{C}_{2} \mathrm{H}_{5} \mathrm{OH}$ from 1:3 to 3:1, and with increased duration of regeneration in solvent from 1 to 5 hours, furan yield increases within the range of $19.3-35.1 \%$, the total activity of the regenerated catalyst is from 23 to $37.6 \%$, selectivity - up to $83.9-95 \%$, duration of the process in the range of $260-300^{\circ} \mathrm{C}$ is $25-36$ hours. Optimal solvent is the mixture of $10 \% \mathrm{H}_{2} \mathrm{C}_{2} \mathrm{O}_{4}: 95 \% \mathrm{C}_{2} \mathrm{H}_{5} \mathrm{OH}$; regeneration time - 4-5 hrs. Subsequently, the spent industrial CDF-1 catalyst was regenerated into the mixture of $10 \% \mathrm{H}_{2} \mathrm{C}_{2} \mathrm{O}_{4}: 95 \% \mathrm{C}_{2} \mathrm{H}_{5} \mathrm{OH}=1: 1$ during 5 hrs.

\section{Results and Discussion}

The activity of spent-regenerated CDF-1 catalyst samples was improved by the first application of the method for their modifying with additives of $d$ - metals from aqueous solutions in the same way (Sokolov, L. A., 1993). Iron, cobalt, and nickel were used as modifying additives. The results for furfural decarbonylation on modified regenerated with transition metal additives batches of spent CDF-1 catalyst are shown in Table 4. The data of Table 4 shows that the application of the regenerated spent CDF-1 catalyst with modifying additives increases its activity in different ways depending on the nature and quantity of the promoters. Thus, with increasing content of iron, cobalt, and nickel from $1.0 \div 3.0$ to $10 \%$ in the content of the regenerated catalyst, yield of the desired product - furan - in the temperature range of $340-380^{\circ} \mathrm{C}$ reached $42.8-51 ., 6 \%$, stability of the catalyst increased from 101 to 136 hours, activity - from 33.6-54.0\%, and selectivity - within $75-96.4 \%$. The greatest activity and stability is demonstrated by the processed regenerated CDF-1 catalyst samples modified with nickel additives.

Table 4. Furfural decarbonylation into furan on regenerated and modified spent CDF-1 catalyst samples

\begin{tabular}{|c|c|c|c|c|c|c|c|c|c|c|c|}
\hline \multirow[b]{2}{*}{$\mathrm{t},{ }^{0} \mathrm{C}$} & \multirow{2}{*}{$\begin{array}{c}\text { Experiment } \\
\text { time, hrs }\end{array}$} & \multirow{2}{*}{$\begin{array}{c}\mathrm{W}_{\phi \phi}, \\
\mathrm{p}^{-1}\end{array}$} & \multirow{2}{*}{$\begin{array}{l}\text { Qty of the } \\
\text { supplied } \\
\text { furfural, } \\
\text { L }\end{array}$} & \multicolumn{6}{|c|}{ Average decarbonylation products yields, $\%$} & \multirow[t]{2}{*}{ Activity, $\%$} & \multirow[t]{2}{*}{ Selectivity, $\%$} \\
\hline & & & & FN & $\mathrm{CH}$ & THF & B-L & FL & $\mathrm{X}$ & & \\
\hline 1 & 2 & 3 & 4 & 5 & 6 & 7 & 8 & 9 & 10 & 11 & 12 \\
\hline \multicolumn{12}{|c|}{ 1. Initial spent CDF-1 catalyst without regeneration and modification } \\
\hline $220-260$ & 12 & 0.010 & 0.12 & 12.0 & 2.0 & 1.3 & 0.5 & 84.6 & 0.05 & 15.6 & 76.9 \\
\hline $260-300$ & 15 & 0.012 & 0.18 & 15.2 & 1.3 & 1.5 & 0.9 & 80.9 & - & 19.1 & 79.5 \\
\hline $300-340$ & 10 & 0.012 & 0.12 & 18.0 & 1.5 & 1.2 & 0.7 & 78.6 & 0.02 & 21.4 & 84.1 \\
\hline $340-380$ & 6 & 0.013 & 0.078 & 13.5 & 2.5 & 1.3 & 1.0 & 82.0 & - & 18.0 & 75.0 \\
\hline Total & 43 & - & 0.498 & - & - & - & - & - & - & - & - \\
\hline \multicolumn{12}{|c|}{ 2. Regenerated CDF-1, without modification } \\
\hline $220-260$ & 18 & 0.010 & 0.18 & 25.0 & 1.52 & 0.05 & - & 73.0 & 0.01 & 27.0 & 92.6 \\
\hline $260-300$ & 30 & 0.012 & 0.36 & 31.0 & 0.86 & 0.8 & - & 67.0 & - & 33.0 & 94.0 \\
\hline $300-340$ & 28 & 0.013 & 0.364 & 37.5 & 1.3 & - & - & 61.0 & - & 39.0 & 96.1 \\
\hline $340-380$ & 15 & 0.015 & 0.225 & 35.0 & 1.4 & - & - & 63.7 & - & 36.4 & 96.1 \\
\hline Total & 101 & - & 1.129 & - & - & - & - & - & - & - & - \\
\hline \multicolumn{12}{|c|}{ 3. Regenerated CDF-1, modified by $3 \% \mathrm{Fe}$} \\
\hline $220-260$ & 20 & 0.010 & 0.200 & 26.0 & 1.7 & 0.5 & 0.05 & 71.7 & 0.02 & 28.3 & 92.0 \\
\hline $260-300$ & 33 & 0.012 & 0.396 & 32.3 & 1.0 & 0.3 & - & 66.4 & - & 33.6 & 96.1 \\
\hline $300-340$ & 30 & 0.013 & 0.390 & 37.6 & 1.2 & - & - & 61.4 & - & 39.0 & 96.4 \\
\hline $340-380$ & 18 & 0.015 & 0.270 & 42.8 & 1.0 & - & - & 56.2 & - & 43.8 & 98.0 \\
\hline Total & 101 & - & 1.256 & - & - & - & - & - & - & - & - \\
\hline \multicolumn{12}{|c|}{ 4. Regenerated CDF-1, modified by $5 \% \mathrm{Fe}$} \\
\hline $230-260$ & 28 & 0.010 & 0.280 & 29.5 & 1.8 & 0.3 & 0.02 & 98.3 & 0.03 & 31.7 & 93.0 \\
\hline $260-280$ & 40 & 0.012 & 0.480 & 38.8 & 1.3 & 0.5 & - & 59.3 & 0.02 & 40.7 & 95.3 \\
\hline $300-340$ & 35 & 0.013 & 0.455 & 42.0 & 0.3 & 0.2 & - & 57.5 & - & 42.5 & 99.0 \\
\hline $340-380$ & 23 & 0.015 & 0.345 & 45.5 & 0.2 & - & - & 54.5 & - & 45.5 & 100 \\
\hline Total & 126 & - & 1.560 & - & - & - & - & - & - & - & - \\
\hline \multicolumn{12}{|c|}{ 5. Regenerated CDF-1, modified by $7 \% \mathrm{Fe}$} \\
\hline $220-260$ & 25 & 0.010 & 0.250 & 28.3 & 1.7 & 0.5 & 0.2 & 69.6 & 0.04 & 30.4 & 94.0 \\
\hline $260-300$ & 35 & 0.012 & 0.420 & 36.0 & 1.3 & 0.3 & - & 62.0 & - & 38.0 & 95.0 \\
\hline $300-340$ & 33 & 0.013 & 0.429 & 40.0 & 1.8 & 0.2 & - & 59.0 & - & 41.0 & 97.6 \\
\hline $340-380$ & 20 & 0.015 & 0.300 & 43.5 & 0.5 & - & - & 56.0 & 0.03 & 44.0 & 99.1 \\
\hline
\end{tabular}




\begin{tabular}{|c|c|c|c|c|c|c|c|c|c|c|c|}
\hline Total & 113 & - & 1.399 & - & - & - & - & - & - & - & - \\
\hline \multicolumn{12}{|c|}{ 6. Regenerated CDF-1, modified by $10 \% \mathrm{Fe}$} \\
\hline $220-260$ & 23 & 0.010 & 0.230 & 26.9 & 1.6 & 0.8 & 0.07 & 70.5 & 0.05 & 29.5 & 91.2 \\
\hline $260-300$ & 35 & 0.012 & 0.420 & 34.0 & 1.4 & 0.7 & - & 64.0 & 0.04 & 36.0 & 94.4 \\
\hline $300-340$ & 32 & 0.013 & 0.416 & 38.5 & 1.2 & 0.35 & - & 60.0 & - & 40.0 & 96.2 \\
\hline $340-380$ & 20 & 0.015 & 0.300 & 42.0 & - & - & - & 58.0 & - & 42.0 & 100.0 \\
\hline Total & 110 & - & 1.366 & - & - & - & - & - & - & - & - \\
\hline \multicolumn{12}{|c|}{ 7. Regenerated CDF-1, modified by $3 \%$ Co } \\
\hline $230-260$ & 23 & 0.012 & 0.276 & 26.8 & 1.8 & 0.4 & 0.6 & 70.0 & 0.04 & 30.0 & 95.3 \\
\hline $260-300$ & 34 & 0.013 & 0.442 & 33.0 & 1.3 & 1.0 & 1.0 & 63.5 & 0.01 & 36.5 & 90.4 \\
\hline $300-340$ & 28 & 0.014 & 0.392 & 40.0 & 1.0 & 1.3 & - & 57.7 & - & 42.5 & 94.1 \\
\hline $340-380$ & 17 & 0.015 & 0.255 & 53.4 & 0.8 & 1.7 & - & 54.0 & - & 46.0 & 94.3 \\
\hline Total & 102 & - & 1.365 & - & - & - & - & - & - & - & - \\
\hline \multicolumn{12}{|c|}{ 8. Regenerated CDF-1, modified by $5 \%$ Co } \\
\hline $230-260$ & 28 & 0.012 & 0.335 & 30.5 & 2.0 & 0.4 & 0.05 & 65.8 & 0.05 & 34.7 & 88.0 \\
\hline $260-300$ & 37 & 0.013 & 0.481 & 39.4 & 1.5 & 0.6 & - & 57.5 & 0.02 & 42.5 & 93.0 \\
\hline $300-340$ & 34 & 0.015 & 0.51 & 44.6 & 0.5 & 0.4 & - & 54.0 & - & 46.0 & 97.0 \\
\hline $340-380$ & 20 & 0.016 & 0.32 & 49.0 & 0.2 & - & 0.04 & 49.7 & - & 50.3 & 97.4 \\
\hline Total & 117 & - & 1.647 & - & - & - & - & - & - & - & - \\
\hline \multicolumn{12}{|c|}{ 9. Regenerated CDF-1, modified by $7 \%$ Co } \\
\hline $230-260$ & 24 & 0.012 & 0.288 & 28.0 & 1.8 & 0.6 & 0.03 & 69.2 & 0.03 & 30.8 & 90.9 \\
\hline $260-300$ & 31 & 0.013 & 0.403 & 36.5 & 1.5 & 0.7 & 0.05 & 61.2 & 0.01 & 38.8 & 94.1 \\
\hline $300-340$ & 27 & 0.015 & 0.405 & 40.0 & 2.0 & 1.0 & - & 56.5 & - & 43.5 & 92.0 \\
\hline $340-380$ & 16 & 0.016 & 0.256 & 43.0 & 1.9 & 1.5 & 0.06 & 53.5 & - & 46.5 & 92.5 \\
\hline Total & 98 & - & 1.352 & - & - & - & - & - & - & - & - \\
\hline \multicolumn{12}{|c|}{ 10. Regenerated CDF-1, modified by $10 \%$ Co } \\
\hline $230-260$ & 22 & 0.012 & 0.264 & 27.3 & 1.9 & 0.8 & 0.05 & 69.8 & 0.04 & 30.2 & 90.4 \\
\hline $260-300$ & 30 & 0.013 & 0.390 & 35.4 & 1.7 & 0.7 & 0.03 & 62.0 & - & 38.0 & 93.1 \\
\hline $300-340$ & 25 & 0.014 & 0.350 & 38.4 & 2.4 & 1.3 & - & 58.0 & 0.01 & 42.0 & 91.4 \\
\hline $340-380$ & 14 & 0.016 & 0.224 & 40.4 & 2.0 & 1.7 & - & 56.7 & - & 43.4 & 93.3 \\
\hline Total & 91 & - & 1.228 & - & - & - & - & - & - & - & - \\
\hline \multicolumn{12}{|c|}{ 11. Regenerated CDF-1, modified by $3 \% \mathrm{Ni}$} \\
\hline $230-260$ & 25 & 0.012 & 0.30 & 28.0 & 1.8 & 0.5 & 0.5 & 69.2 & Sl. & 30.8 & 91.0 \\
\hline $260-300$ & 35 & 0.013 & 0.455 & 35.0 & 1.3 & 1.2 & 0.9 & 62.6 & - & 37.4 & 93.4 \\
\hline $300-340$ & 30 & 0.015 & 0.450 & 42.5 & 0.8 & 1.7 & - & 55.0 & - & 45.0 & 94.4 \\
\hline $340-380$ & 20 & 0.016 & 0.32 & 45.3 & 0.6 & 2.0 & - & 53.0 & - & 47.0 & 96.4 \\
\hline Total & 110 & - & 1.525 & - & - & - & - & - & - & - & - \\
\hline \multicolumn{12}{|c|}{ 12. Regenerated CDF-1, modified by $5 \mathrm{Ni}$} \\
\hline $230-260$ & 30 & 0.012 & 0.36 & 31.5 & 2.5 & 1.0 & 0.3 & 65.0 & 0.4 & 35.0 & 90.0 \\
\hline $260-300$ & $42=$ &, 013 & 0.546 & 41.0 & 1.8 & 1.7 & 0.2 & 55.0 & 0.1 & 45.0 & 93.3 \\
\hline $300-340$ & 39 & 0.015 & 0.585 & 46.5 & 0.9 & 2.3 & - & 51.0 & - & 49.0 & 95.0 \\
\hline $340-380$ & 25 & 0.016 & 0.40 & 51.6 & 0.5 & 2.5 & - & 46.0 & - & 54.0 & 95.5 \\
\hline \multicolumn{12}{|c|}{ 13. Regenerated CDF-1, modified by $7 \% \mathrm{Ni}$} \\
\hline $230-260$ & 33 & 0.012 & 0.396 & 30.0 & 1.8 & 1.3 & 0.5 & 97.0 & 0.05 & 33.0 & 90.9 \\
\hline $260-300$ & 46 & 0.013 & 0.598 & 40.0 & 2.0 & 1.9 & 0.6 & 56.0 & 0.03 & 44.0 & 90.9 \\
\hline $300-340$ & 42 & 0.015 & 0.630 & 43.0 & 1.2 & 3.0 & 0.8 & 53.0 & - & 47.0 & 91.5 \\
\hline $340-380$ & 29 & 0.016 & 0.464 & 50.0 & 1.0 & 2.3 & 0.1 & 46.6 & - & 53.4 & 93.6 \\
\hline Total & 150 & - & 2.088 & - & - & - & - & - & - & - & - \\
\hline \multicolumn{12}{|c|}{ 14. Regenerated CDF-1, modified by $10 \% \mathrm{Ni}$} \\
\hline $230-260$ & 30 & 0.012 & 0.30 & 28.9 & 1.9 & 0.9 & 0.6 & 67.0 & 0.03 & 33.0 & 87.6 \\
\hline $260-300$ & 35 & 0.013 & 0.455 & 36.4 & 1.5 & 2.0 & 0.8 & 60.0 & 0.02 & 40.0 & 91.0 \\
\hline $300-340$ & 30 & 0.013 & 0.39 & 41.9 & 1.5 & 2.8 & 0.4 & 54.6 & - & 45.4 & 92.3 \\
\hline $340-380$ & 20 & 0.014 & 0.28 & 46.5 & 1.3 & 2.5 & 0.2 & 50.0 & - & 50.0 & 93.0 \\
\hline Total & 115 & - & 1.425 & - & - & - & - & - & - & - & - \\
\hline
\end{tabular}

Promoting additives for enhancing activity of the spent catalyst are arranged in series: $\mathrm{Fe}<\mathrm{Co}<\mathrm{Ni}$. 
Thus, modifying regenerated spent CDF-1 catalyst transition metals additives significantly increase furan activity, selectivity, and stability.

The XPS-analysis was applied to the catalysts studied above. Results of the XPS-study of fresh, spent, regenerated, and regenerated-modified by cobalt and nickel additives samples of CDF-1 indicate that the supported catalysts and their distribution elements are dependent on the processing content. Fresh CDF-1 contains $42 \%$ at. $\mathrm{Pd}^{2+}$ and $58 \%$ at. $\mathrm{Cs}^{+}$, relatively big amount of adsorbed water (Eru. $01 \mathrm{~S}-532,5 \mathrm{eV}$ ) and significant amount of carbon. In all cases, carbon hag one line with IS belonging to coal with bond energy Eru $=285.0 \mathrm{eV}$.

After the catalytic process, the oxidation level and the metal content on CDF-1 surface was not changed, but the carbon content increased significantly.

Regeneration reduces the catalyst surface carbonisation, but also significantly changes the state of the metals. The regenerated catalyst already has $94 \%$ at. Pd, which is present in two states with Eru $=336.9$ and $339.0 \mathrm{eV}$. The first of these relates to $\mathrm{PdO}$, and the second can be interpreted as either $\mathrm{Pd}^{4+}$ or, more likely, to a hydrated form of $\mathrm{PdO} \bullet \mathrm{nH}_{2} \mathrm{O}$. Obviously, the enrichment of catalyst surface with palladium during regeneration is explained in more strong interaction with $\mathrm{Pd}_{2} \mathrm{C}_{2} \mathrm{O}_{4}$ compared to the same with Cs.

In regenerated CDF-1 catalysts modified with nickel, the element distribution on surface differs substantially from the unpromoted ones. $\mathrm{Pd}^{2+}$ content is much lower (18 at.\%), and here it is fully in the hydrated form. Presumably, $\mathrm{H}_{2} \mathrm{C}_{2} \mathrm{O}_{4}$ more actively reacts with $\mathrm{Ni}$, than with $\mathrm{Pd}$, whereby the content of $\mathrm{Ni}^{2+}$ (as in hydroxide form) on the surface reaches 44 at.\%. This catalysi is less carbonised. The most likely state of the cesium in the catalyst is $\mathrm{Cs}^{+}-$ion $(\mathrm{Eru}=723.8 \mathrm{eV})$. However, it shall be considered that the shift of the bond energy at the transition from $\mathrm{CS}^{2+}$ to, let us suppose, $\mathrm{CsF}$ is only $0.3 \mathrm{eV}$, while the spectrometer resolution is $0.3 \mathrm{eV}$.

Therefore, for the given element and due to the superposition of the different states responses, there is uncertainty in the determination of the state, which can be seen only tentatively (Yakovlev, M. M., 2012). CDF-1 promoted by cobalt and after the regeneration contains the least amount of carbon and oxygen. Cobalt reacts with $\mathrm{H}_{2} \mathrm{C}_{2} \mathrm{O}_{4}$ stronger than with $\mathrm{Ni} 89$ at.\%, catalyst metal surface is covered with $\mathrm{Co}^{2+}$ in the form of oxide and hydroxide. Oxides $\mathrm{Pd}^{2+}$ and $\mathrm{Cs}^{+}$comprise, respectively, 8 and 3 at.\%. Apparently, cobalt is in highly dispersed form in this catalyst.

Thus, the regeneration of the spent CDF-1 catalyst significantly increases the surface concentration of palladium in the form of $\mathrm{PdO}$ and $\mathrm{PdO} \cdot \mathrm{nH}_{2} \mathrm{O}$. Modification of the regenerated catalyst with nickel or cobalt additives reduces the surface concentration of both palladium forms due to the appearance of nickel and cobalt oxides and hydrides. Regeneration and modification of the regenerated catalyst reduce the surface concentration of $\mathrm{Cs}_{2} \mathrm{O}$.

The main decarbonilating compound was five-membered heterocyclic aldehyde of furans - furfural (m.v. 96.06; $\mathrm{t}_{\mathrm{k}}$-I62 ${ }^{\circ} \mathrm{C}$ ), obtained by acid hydrolysis or acid-free hydrolysis of wood and agricultural waste.

Regeneration of spent catalyst: spent industrial CDF-1 catalyst batch was regenerated in mixtures $6,10,20 \%$ of aqueous solutions of oxalic acid $\left(\mathrm{H}_{2} \mathrm{C}_{2} \mathrm{O}_{4}\right)$ and $95 \% \mathrm{C}_{2} \mathrm{H}_{2} \mathrm{OH} \quad(1: 1,1: 2,1: 3$ or $2: 1,3: 1)$.

CDF-1 catalyst regenerated in a solvent was modified with iron, cobalt, and nickel additives. Nitrate salts: $\mathrm{Fe}\left(\mathrm{NO}_{3}\right)_{3}, \mathrm{Co}\left(\mathrm{NO}_{3}\right)_{3}, \mathrm{Ni}\left(\mathrm{NO}_{3}\right)_{3}$ were dissolved in $200 \mathrm{~cm}^{3}$ water at a temperature of $50^{\circ} \mathrm{C}$. The $1.3,5,7,10 \%$ (by weight of the regenerated CDF-1 catalyst) aqueous solutions of these salts were prepared. Further, the solutions with constant stirring received the appropriate amounts of the regenerated CDF-1 CATALYST AND received gradually poured in portions the $10 \%$ sodium hydroxide solution. At that, ions entering the metal hydroxides are precipitated on the regenerated CDF-1 catalyst tablets. Completeness of metal precipitation on the catalyst was monitored by the disappearance of colour and formation of a clear solution. Regenerate and modified catalyst was washed from alkali until neutral to phenolphthalein reaction appeared, then dried in an oven.

Furfural decarbonylation reaction was performed on a column-type flow unit consisting of sequentially (vertically) connected heater and reactor. Hydrogen and furfural were supplied into the heater from the bottom heater and into the reactor - from the top.

Each experiment used $65 \mathrm{~cm}^{3}(37,5 \mathrm{~g})$ of CDF-1 catalyst with particle size of 3-4 $\mathrm{mm}$. The temperature in the preheater was maintained within $200-220^{\circ} \mathrm{C}$ and in the reactor, it was gradually increased from 220 to $380^{\circ} \mathrm{C}$; hydrogen pressure was of $1 \mathrm{MPa}$. The rate of hydrogen bubbling was $18 \mathrm{~L} /$ hour, volumetric rate (for liquid furfural) was varied from 0.015 to $0.024 \mathrm{~L} /$ hour. Frequency of sampling for analysis was 1 hour. The catalyst activity is expressed in $\%$ of furfural conversion per pass; selectivity (\%) - on the furan yield from the converted furfural; catalyst operation stability - in relation to the minimum furfural conversion to the minimum overall for 
the entire period or total duration (in hours) of the catalysts operation in the range $220-380^{\circ} \mathrm{C}$ of the process.

\section{Conclusions.}

We propose a method for regenerating catalyst for furfural decarbonylation by treating the spent catalyst with a solvent containing $6,10,20 \%$ of aqueous solution of oxalic acid $\left(\mathrm{H}_{2} \mathrm{C}_{2} \mathrm{O}_{4}\right)$ and $95 \%$ of $\mathrm{C}_{2} \mathrm{H}_{2} \mathrm{OH} \quad(1: 1,1: 2$, $1: 3$ or $2: 1,3: 1)$.

To improve the activity of spent-regenerated samples of CDF-1 catalyst, the method of modifying with d-metals additives from aqueous solutions was applied. Results for furfural decarbonylation on additives regenerated-modified with d-transition metals batches of spent CDF-1 catalyst shows that implementing spent modifying additives to the regenerated catalyst increases the stability and activity.

\section{References}

Babenko, V. S. (1983). Regularities of the regeneration of catalysts based on metal oxides of iron and chromium subgroups of carbonaceous deposits. Abstract of a thesis of the candidate of chemical sciences. Novosibirsk, 16.

Babenko, V. S. et al. (1982). Carbonaceous deposits burn-off from the iron oxide catalyst promoted with alkali metals. Kinetics and Catalysis, 23(4), 977-982.

Babenko, V. S., \& Buyanov, R. A. (1986). Regularities of self-regeneration of oxide iron-potassium catalysts in the presence of water steam. Kinetics and Catalysis, 27(2), 509-513.

Babenko, V. S., \& Buyanov, R. A. et al. (1979). Study of carbon deposit burn-off from carbonized cobalt, and nikel oxides. Kinetics and catalysis, 20(1), 212-217.

Babenko, V. S., \& Buyanov, R. A. et al. (1982). Study of carbonized chromium oxide and peculiarities of its regeneration. Kinetics and catalysis, 23(3), 729-733.

Babenko, V. S., Buyanov, R. A., \& Afanasiev, A. D. (1982). Carbon deposits burn-off on the iron oxide catalysts promoted with potassium. Kinetics and catalysis, 23(1), 131-137, 286.

Beisekov, T. B., \& Bitemirova, A. E. et al. (1990). A.S.1617717 (USSR). The method for regenerating spent catalyst from furan production.

Bitemirova, A. (2013). The methods for preparation of furan. Seattle-2013:4 $4^{\text {th }}$ International Academic Research Conference on Business, Education, Nature and Technology (4-5 November, 2013, Seattle, W. A )

Bitemirova, A. E., Baimakhanova, G. M., \& Kerimbaieva, K. Z. (2013). On the mechanism of catalysts coking. "Sociosphere" Russia, Penza (RSCI) No. 3, 2013.

Buyanov, R. A. (1967). Coking and regeneration of dehydrogenation catalysts in the preparation of GK monomers. Novosibirsk: Nauka. 64.

Buyanov, R. A. (1983). Catalysts coking. Novosibirsk: Nauka, 207.

Fedotova, S. A., \& Tsirmin, Yu. A. (1975). On the nature of deposits on furfural columns plates. GLHP, 1, 8-9.

Gardos, Gy, Pechy, Z., Csaszar, E., \& Redey, A. (1976). Investigation of furfural decarbonylation over metal palladium Catalysts. Hung. J.Industr. Chem., 4, 125-138.

Giller, S. A., Karmilchik, A. Ya., Shimanskaya, M. V., \& Avots, A. A. (1976). Contact decarbonylation and hydrogenolysis of the main components of the stillage residue of furfural production. Using pentose-containing raw material. Riga: Zinatna, 261-262.

Giller, S. A., Karmilchik, A. Ya., \& Aswot, A. A. et al. (1970). New technology for obtaining furan. Hydrolysis forest chemical industry, 9-11.

Kramerova, G. E. (1988). Regularities of furfural catalytic decarbonylation regeneration. Journal of applied chemistry, TL XI, 112, P.2719, 4-15.

M Yerzhanova, T. B., \& Beysekov et al. (1975). A.S. 468648 (USSR). Catalyst for producing furfuryl alcohol. Published in B. I., 116.

Samakhov, A. A., \& Zaidman, A. M. et al. (1976). On changing catalyst activity during use. Novosibirsk: Nauka, 108.

Sokolova, L. A. (1993). Adsorptive and catalytic properties of the catalysts on alumina oxide. Catalytic reactions 
in the liquid phase. Almaty, 21-25.

Sokolova, V. N., Shevchenko, V. S., \& Boldyrev, A. V. et al. (1981). Status and prospects of development of production based on catalytic processing of furfural. The problem of using pentose-containing raw material. Riga: Zinatne, 61-64.

Yakovlev, M. M. (2012). Reaktsiya furfurola s peroksidom vodoroda pri vozdeystvii postoyannogo elektricheskogo toka i sintezy gidrofuranonov na ee osnove [The reaction of furfural with hydrogen peroxide under infl uence of constant current and syntheses of hydrofuranones on its basis]: Dis. cand. chem. sci., Krasnodar, 157.

Caca, J., Morrondo, E. S., Parra, J. B., \& Sostre, H. (1982). Properties of some Catalystsuben for the decarbonylation of furfural. Reaction Kineties Catalysis Zetters, 20(3/4).

\section{Copyrights}

Copyright for this article is retained by the author(s), with first publication rights granted to the journal.

This is an open-access article distributed under the terms and conditions of the Creative Commons Attribution license (http://creativecommons.org/licenses/by/3.0/). 